\title{
Evaluación de la competencia profesional en personas con discapacidad intelectual. Una propuesta de adaptación de la metodología e instrumentos INCUAL para la igualdad de oportunidades
}

\author{
Evaluation of professional competence of people with intellectual \\ disability. A proposal of adaptation of the INCUAL methodology \\ and instruments for equal opportunities
}

\section{Resumen}

La incorporación efectiva al empleo de las personas con discapacidad intelectual requiere atender especialmente a los procesos de transición a la vida adulta, con la formación y la orientación laboral como estrategias relevantes. La posibilidad de demostrar lo que son capaces de hacer mediante pruebas adecuadas para ello, además de avanzar en la igualdad de oportunidades, representaría un proceso de habilitación para la inserción laboral. Desde esta perspectiva, tomando como referencia las orientaciones del Instituto Nacional de las Cualificaciones (INCUAL), se ha procedido a adaptar y aplicar los instrumentos de evaluación de competencias profesionales para determinar la capacidad de desempeño del perfil profesional de operaciones básicas de montaje del alumnado con discapacidad intelectual de un centro ocupacional. Los resultados confirman la validez de la adaptación, la ampliación de posibilidades de inserción laboral en la Comarca do Sar (Galicia), así como el efecto retroalimentador en los itinerarios formativos y de orientación laboral del centro.

\section{Palabras clave}

Discapacidad intelectual, evaluación de competencias, igualdad de oportunidades, inserción laboral, inclusión social, centro ocupacional.

\section{Abstract}

The effective incorporation of people with intellectual disability to employment requires special attention to the process of transition to adulthood. In this context the strategies related to training and career advice are especially relevant. The possibility of showing what they are capable of doing through appropriate testing, as well as advancing in equal opportunities, would present a process of habilitation for their employment. From this perspective, taking as reference the guidelines of National Institute for Qualifications (INCUAL), a process of adaptation and application has been carried out of the instruments for evaluation of professional competences to determine the ability of performance of the professional profile of basic assembly operations of students with intellectual disability of an occupational centre. The results confirm the validity of the adaptation, the enlargement of the possibilities of job placement in Comarca do Sar (Galicia, Spain), as well as the feedback effect in training itineraries and career advice in the centre.

\section{Keywords}

Intellectual disability, evaluation of competences, equal opportunities, employment, social inclusion, occupational centre.

\section{Gonzalo Docampo Núñez \\ <gdocampo@edu.xunta.es> \\ Profesor de Servicios Socioculturales y a la Comunidad. Consellería de Cultura, Educación e Ordenación Universitaria de la Xunta de Galicia}

\section{Carmen Morán de Castro <carmen.moran@usc.es>}

Universidad de Santiago de Compostela

\author{
Para citar: \\ Docampo Núñez, G. y Morán de \\ Castro, M. C. (2OI4): "Evaluación \\ de la competencia profesional en \\ personas con discapacidad intelectual. \\ Una propuesta de adaptación de la \\ metodología e instrumentos INCUAL \\ para la igualdad de oportunidades". \\ Revista Española de Discapacidad, \\ $2(\mathrm{I}):$ 7I-96. \\ $<\mathrm{http}: / /$ dx.doi.org/IO.5569/2340- \\ 5104.02.01.04>
}

Fecha de recepción: 24-03-20I4 Fecha de aceptación: 30-05-20I4 


\section{Introducción}

La igualdad de oportunidades, pero también de resultados, constituyen los derechos irrenunciables sobre los que deben asentarse las estrategias y acciones orientadas a la inclusión social de toda la ciudadanía, derechos tanto más insoslayables cuando se trata de avanzar en equidad con el colectivo de personas con discapacidad, que precisa compensar las desventajas de partida para la participación normalizada en su contexto económico y sociocultural. Desde esta convicción se desarrolla este artículo, que aborda el ámbito de la inclusión laboral de las personas con discapacidad intelectual (PcDI) como antesala o requisito para su inclusión social, a través de la formación y posterior evaluación de la competencia profesional.

Partimos conceptualmente de dos premisas. La primera, asumir que el desarrollo comunitario no será pleno si no incluye a todos los colectivos de la comunidad (Caride et al., 2007). La segunda, que la inserción laboral de las PcDI, tal y como se justificará a lo largo de este artículo, es un paso de especial relevancia en el logro de su inclusión social. En este sentido, el diseño de instrumentos adaptados para la evaluación de competencias abre caminos para que estas personas puedan ser evaluadas por lo que realmente "saben hacer", lo que permitirá superar las dificultades reiteradas a la hora de demostrar sus habilidades, por la inadecuación de los métodos utilizados.

La formación para el trabajo toma en la actualidad como referencia fundamental el término "competencia", directamente vinculado a la resolución de los problemas e interrogantes que la innovación tecnológica y la globalización económica imponen. Consecuentemente, en la Formación Profesional actual la evaluación y acreditación de cualificaciones y competencias profesionales cobra un gran protagonismo, y se toma como referencia en estos procesos el Catálogo Nacional de Cualificaciones Profesionales, elaborado por el Instituto
Nacional de las Cualificaciones (INCUAL). Este catálogo es el referente para acreditar formalmente las competencias adquiridas mediante la experiencia profesional.

La oportunidad de realizar la adaptación del proceso e instrumentos de evaluación de competencias que describimos se materializó en el Centro Ocupacional de Sorribas, de la Asociación AMIPA, situada en el Ayuntamiento de Rois (A Coruña). En el marco del Programa de Transición a la Vida Adulta, AMIPA desarrollaba una acción formativa sobre operaciones de fabricación y montaje de accesorios y complementos de aluminio, con el objetivo de capacitar al alumnado en un sector productivo del entorno y, por lo tanto, con posibilidades reales de contratación de las personas participantes. Esta ocasión se nos ofreció como una oportunidad óptima para comprobar, con instrumentos fiables, el grado de cumplimiento, por parte del alumnado, de los requisitos establecidos en el Catálogo Nacional de Cualificaciones Profesionales para acreditar el perfil profesional requerido en el desempeño de una ocupación, y con ello, que las propuestas de inserción laboral que se promoviesen incrementaran su nivel de logro. Así pues, se procedió a realizar una adaptación de la metodología e instrumentos de evaluación previstos por el INCUAL al colectivo de PcDI, tomando la observación como estrategia fundamental de recogida de datos sobre las capacidades de las personas evaluadas para "saber haciendo" (conjugación que se realiza en esta propuesta del "saber" y "saber hacer") y "saber estar".

\section{Discapacidad intelectual y habilidades conceptuales, sociales y prácticas}

El concepto de discapacidad intelectual evoluciona decidida y progresivamente en la sustitución de enfoques médicos y psicopatológicos por otras concepciones más funcionales y dinámicas, centradas en evaluar 
las necesidades de la persona de manera comprensiva, y en determinar el modo más eficaz de prestar los apoyos que necesita para maximizar su desarrollo personal y calidad de vida (Amor, 20I0).

Desde su primera definición, en I908, la Asociación Americana de Discapacidades Intelectuales y del Desarrollo (AAIDD) ha ido elaborando un amplio trabajo de conceptualización teniendo en cuenta los avances científicos, pedagógicos y sociales, así como los cambios en la práctica clínica y la reflexión ética, lo que hace de esta organización el principal referente mundial en este ámbito.

Pero ha sido en las últimas décadas cuando la definición ha experimentado una auténtica revolución conceptual, introduciéndose aspectos relativos a la orientación funcional, el énfasis en los apoyos o los tres criterios de diagnóstico (inteligencia, conducta adaptativa y edad de comienzo); asumiendo además el firme compromiso de desarrollar un sistema de clasificación que incorpore los resultados proporcionados por la investigación sobre evaluación y determinación de intensidad de los apoyos; y añadiendo mayor precisión en la medición de la inteligencia y la conducta adaptativa organizada en torno a las habilidades conceptuales, sociales y prácticas ${ }^{\mathrm{I}}$.

La hasta el momento última definición de discapacidad intelectual de la AAIDD $\left(\mathrm{II}^{\mathrm{a}}\right)$, elaborada por Schalock et al. (2010), introduce como novedad más evidente el cambio de terminología, eliminando definitivamente la expresión "retraso mental":

"La discapacidad intelectual se caracteriza por limitaciones significativas tanto en funcionamiento intelectual como en conducta adaptativa tal y como se manifiesta en

I. Estas habilidades referidas a la conducta adaptativa de las personas con discapacidad intelectual tienen su correlato en el ámbito de la evaluación de competencias profesionales en términos de "saber", "saber estar" y "saber hacer", los cuales, por otra parte, se relacionan, a su vez, con la tradicional categorización evaluativa de conceptos, actitudes y procedimientos. habilidades adaptativas conceptuales, sociales y prácticas. Esta discapacidad aparece antes de los I 8 años".

Ante esta nueva definición, Verdugo y Schalock (20IO: I2) señalan ciertas premisas de aplicación, ya contempladas en la anterior definición, formulada en 2002:

"Para la aplicación de esta definición hay que tener en cuenta cinco premisas:

- Las limitaciones en el funcionamiento actual deben considerarse en el contexto de ambientes comunitarios típicos de los iguales en edad y cultura.

- Las evaluaciones válidas tienen en cuenta la diversidad cultural y lingüística, así como las diferencias en comunicación y en aspectos sensoriales, motores y comportamentales.

- En el individuo, las limitaciones a menudo coexisten con las capacidades.

- Un importante propósito de describir las limitaciones es el desarrollo del perfil de los apoyos necesarios.

- Si durante un período de tiempo prolongado ponemos en marcha los apoyos personalizados apropiados, por lo general, mejorará el funcionamiento vital de la persona con discapacidad intelectual”.

Del enfoque multidimensional contenido en esta definición se derivan implicaciones para los servicios socioeducativos, con una exposición de las funciones habituales que se centran en el diagnóstico, la clasificación y la provisión de apoyos individualizados. Siguiendo a Luckasson et al. (2002: I 5 I), se entiende por apoyo una serie de "recursos y estrategias que pretenden promover el desarrollo, educación, intereses y bienestar personal, y que mejoran el funcionamiento individual". Los autores proponen una tipología de apoyos a PcDI, ordenándolos de menor a mayor intensidad en intermitentes, limitados, extensos y generalizados ${ }^{2}$.

2. Los apoyos intermitentes son de naturaleza episódica; la PcDI precisa este tipo de apoyo en momentos de transición 
Estos apoyos constituyen un elemento esencial para la adaptación del proceso e instrumentos de evaluación de competencias profesionales y para la orientación laboral de las PcDI, como se describen en este trabajo.

\section{Transición a la vida adulta de las personas con discapacidad intelectual. La formación y la orientación laboral como factores esenciales para la inserción laboral}

Para aproximarnos al concepto de transición a la vida adulta en la discapacidad intelectual, tomamos como referencia las características de este proceso en la generalidad de jóvenes en tránsito a la adultez, en la certeza de que las dificultades que conlleva serán de mayores proporciones para las personas con discapacidad, máxime si tenemos en cuenta que éstas pueden iniciar esta transición en edades cronológicas avanzadas. El interés científico por descubrir cuáles son las estrategias que pueden permitirles una mayor participación social ha ido aumentando, pero continúa existiendo gran desconocimiento sobre cómo afrontar o facilitar este cambio, que es descrito por Jurado (I999: I34) de la siguiente forma:

$$
\begin{aligned}
& \text { "Por transición debe entenderse todo episodio } \\
& \text { o fase que se conforma como aspecto } \\
& \text { crítico que ocurre durante los cambios, sean } \\
& \text { madurativos, sociales o de otra índole, que } \\
& \text { afectan al individuo y que se caracterizan por } \\
& \text { las repercusiones que tienen en el ambiente o } \\
& \text { contexto en el que ocurren". }
\end{aligned}
$$

Otra descripción de transición a la vida adulta fue aportada por Pallisera (I996),

del ciclo vital y pueden variar el nivel de intensidad. Los limitados, aunque restringidos, son apoyos consistentes a lo largo del tiempo. Los extensos son apoyos regulares (diarios) en algunos entornos y sin limitación temporal. Los generalizados se caracterizan por la constancia y la elevada intensidad que se proporciona en los distintos entornos y pueden mantenerse de por vida; comprometen a un mayor número de personas en el equipo de apoyo y presentan mayor grado de intrusión en la vida del individuo. interpretándola como el resultado de la combinación de los intereses y motivaciones con los recursos personales y oportunidades sociales del individuo para poder hacerla realidad.

Lo cierto es que los cambios económicos, tecnológicos y sociales producen situaciones nuevas y complejas en la transición de la juventud a la vida adulta y activa. Además, las sucesivas intervenciones de los Gobiernos en materia de legislación laboral modifican continuamente la organización del trabajo y la configuración resultante del mercado laboral. Señalaba al respecto Pallisera (ibíd.) que este tipo de actuación favorece la emergencia de un modelo de transición a la vida adulta dominado por la incerteza y la precariedad de acceso al primer empleo, condicionado por una creciente temporalidad y flexibilidad en la organización de la producción y de las funciones profesionales; consecuentemente, el cambio frecuente de ocupación, con el consiguiente cambio de funciones y estatus laboral, se instala como tendencia.

La enorme incidencia del desempleo, con cifras que actualmente alcanzan máximos históricos a raíz de la crisis económica (tasa de paro del $26,03 \%$ y tasa de paro en menores de 25 años del 55,06\%) [INE, 20I4], altera las actitudes, aspiraciones y pautas de comportamiento de muchos jóvenes, retrasando cada vez más el momento de emancipación de la familia, al tiempo que se prolonga el período de formación académica.

Será preciso tomar conciencia de algunos fenómenos y de las limitaciones objetivas y subjetivas que encontraremos en relación a las personas con discapacidad, ya que, como señala Hegarty (I994), la transición de la escuela a la vida adulta supone dejar atrás la infancia y la necesidad de preparación y formación para el futuro. Dicha preparación debe abarcar aspectos tales como el trabajo, la independencia, la vida social y la vida doméstica, siendo la integración y la asignación de roles en la vida real la forma de habilitación/rehabilitación más eficaz. Es fundamental, en este sentido, preparar a las personas con discapacidad desde una perspectiva 
polivalente (Jurado, I999) que persiga una ampliación del abanico de alternativas/ posibilidades en relación a las tareas susceptibles de ser desempeñadas, sin dejar de lado la participación en el medio sociocomunitario.

Durante la etapa escolar, apenas se realiza un trabajo sistemático en contenidos favorecedores de la posterior inclusión laboral de las personas con discapacidad. Fullana et al., (2010), en su estudio sobre la contribución de la Educación Secundaria Obligatoria a la inclusión laboral del alumnado con discapacidad intelectual, señalan cómo, en líneas generales, las propuestas que se desarrollan tienen un carácter más orientador que formativo. Es por este motivo por lo que la formación que la PcDI recibe posteriormente tiene una importancia fundamental para su inclusión laboral, al incidir notablemente en sus motivaciones e intereses, además de aportarle herramientas con las que incrementar su abanico de oportunidades.

La etapa adulta supone un período excelente para continuar un proceso formativo centrado en las habilidades adaptativas. Es un momento del ciclo vital que requiere redoblar los esfuerzos, garantizar los apoyos necesarios y potenciar al máximo las capacidades de las PcDI. Además, finalizado el período escolar, las personas que tuvieron acceso a la integración escolar suelen demandar la continuidad en un sistema ordinario que les permita una inserción social en el sentido amplio de la palabra. De esta manera, siguiendo a Pérez (20I I), no podemos hablar de igualdad de oportunidades si no somos capaces de integrar a los individuos en el mercado de trabajo, dado que una verdadera inserción social es de carácter sociolaboral.

La complejidad de la integración sociolaboral de estas personas justifica la necesidad de planificar un conjunto de acciones formativas específicas, puesto que para desempeñar un trabajo necesitan la preparación y formación adecuadas. Por ello, la formación en habilidades y competencias prelaborales debe discurrir paralela a la formación ocupacional específica, ya que se ha comprobado que las principales dificultades en el mantenimiento del puesto de trabajo no derivan de la ejecución de las tareas asignadas, sino de la dificultad para mostrar un comportamiento maduro acorde con las exigencias del entorno laboral, situación que viene dada, en muchos casos, por la carencia de una orientación laboral adecuada. Tengamos además en cuenta que una gran parte del colectivo de PcDI tiene seriamente limitado su repertorio de habilidades sociales, especialmente las requeridas en contextos complejos como son los entornos laborales. Por lo tanto, la formación que se les proporcione debe basarse en las capacidades y potencialidades del individuo a través de sistemas metodológicos y didácticos favorecedores del desarrollo de aprendizajes, habilidades y destrezas que mejoren su empleabilidad. Paralelamente, señalan Izuzquiza y Ruiz (2005), la formación previa a la incorporación laboral produce en el entorno familiar nuevas dinámicas de relación que favorecen un papel más adulto de la PcDI y modifican las actitudes paternalistas.

Consecuentemente, la formación laboral debe dirigirse hacia el pleno desarrollo de la persona. Frente a enfoques tradicionales de la formación basada en el conocimiento, el enfoque de la formación basada en la competencia reivindica el carácter instrumental: adquirir las competencias profesionales requeridas en el empleo, lo cual implica conseguir conocimientos sobre conceptos, pero también sobre procedimientos y actitudes. Estos aspectos dotarán a las personas de una coherencia interna que, como señala Riaño (2OI2), se concretará no sólo en el trabajo, sino en aspectos familiares, culturales y sociales, estableciendo un vínculo entre las distintas dimensiones de la vida.

Trabajar, como subrayan De Miguel y Cerrillo (2010), es esencial para la plena realización humana; tener la oportunidad de desarrollar una ocupación y sentirnos competentes en ella significa que somos capaces de "hacer", que aportamos una efectiva contribución social y económica. Las PcDI quieren aprender a hacer y ser tenidas en cuenta en la esfera laboral más allá de los centros ocupacionales (FEAPS, I995). Esto requiere, inexcusablemente, el desarrollo de procesos innovadores en la formación 
tradicional, cuyos métodos de evaluación resultan con frecuencia inalcanzables para ellas: las PcDI deben ser evaluadas conforme a lo que son capaces de hacer, es decir, centrándose más en sus competencias (Jurado, I999) que en los conocimientos que sean capaces de exhibir en una prueba, por lo general, escasamente propicia a la demostración de desempeño en una tarea para este colectivo.

Los enfoques formativos basados en competencias "tratan de reducir el hiato entre el mundo educativo y el del trabajo, entre la formación teórica y la formación práctica, entre la competencia académica y la profesional" (Blanco, 2008: 33). Por ello, la formación laboral en competencias y la orientación serán básicas para la integración laboral de las PcDI, considerándose una actuación esencial desde el inicio de los programas hasta su finalización (Izuzquiza y Ruiz, 2005; Egido et al., 2009). El asesoramiento laboral y la orientación personal y profesional a la PcDI y, en su caso, a su familia y al entorno laboral que acoge a la persona trabajadora, son factores esenciales para el éxito tanto en los centros ocupacionales como en los centros especiales de empleo y el empleo con apoyo. Es necesario proporcionar a la persona con discapacidad una formación previa muy ajustada a los requisitos del perfil laboral que va a desarrollar y un apoyo individualizado a lo largo de todo el proceso, lo que supone, según Ibáñez y Mudarra (2007), un trabajo específico del orientador profesional prioritariamente en los siguientes aspectos: la toma de conciencia de oportunidades; la conciencia y el conocimiento de sí mismos como individuos únicos; la capacidad para la toma de decisiones; el aprendizaje para las transiciones propias del crecimiento personal, y mediante el fomento de la adquisición de las destrezas necesarias para afrontarlas.

Diferentes perspectivas sugieren cómo en la actualidad el trabajo trasciende el reduccionismo económico que lo caracterizaba en otras épocas, superando la restricción de su finalidad a la cobertura de las necesidades de subsistencia y a la acumulación de bienes materiales. Como subraya el Colectivo Ioé (2003), los hombres y las mujeres en edad laboral despliegan estrategias destinadas a conseguir independencia y reconocimiento social como sujetos activos que son capaces de desarrollar un proyecto de vida propio. De todos los factores que intervienen en las limitaciones de la persona con discapacidad para lograr su adaptación al medio, la integración social y, finalmente, su independencia, uno de los que con mayor intensidad incide es, sin duda, la exclusión del mundo del trabajo. Toda persona con discapacidad, pero con potencialidades susceptibles de convertirse en valor útil, debe ser considerada per se como capaz de desempeñar una actividad laboral. Cualquier nivel de marginación en esta área va a suponer para estas personas una razón más para su aislamiento y el consiguiente deterioro de su proyecto personal.

Pero no todos los tipos de discapacidad presentan las mismas dificultades para la integración laboral. Mientras que las personas con discapacidades motrices o sensoriales pueden, en muchas ocasiones, conseguir y mantener un empleo mediante la realización de adaptaciones del entorno laboral relativamente sencillas, las PcDI requieren, por lo general, adaptaciones y cambios más profundos (Alba y Moreno, 2004). En cualquier caso, la formación ha demostrado ser determinante en el acceso al mundo del trabajo y, por tanto, en su integración en la sociedad. Específicamente en la discapacidad intelectual, se ha constatado cómo las personas pueden obtener resultados positivos cuando se desarrollan todas sus capacidades laborales y se las introduce en el mundo del trabajo de forma pautada, real y apoyada en la práctica ocupacional diaria y, naturalmente, se les asignan tareas apropiadas a sus motivaciones y aptitudes. Este posibilismo infelizmente se debilita ante la contundencia de los datos estadísticos. Un 4,8\% de la población española en edad laboral tiene alguna discapacidad reconocida, lo que supone un incremento de I $5 \%$ respecto a 20 I I. Las tasas de actividad y empleo de este grupo son 40 y 23 puntos inferiores, respectivamente, a las del conjunto de la población (Tabla I), y la tasa de paro, 8 puntos superior. 
Tabla 1. Tasas de actividad, empleo y paro. España, 2012 (\%)

\begin{tabular}{|l|c|c|c|}
\hline & $\begin{array}{c}\text { Personas sin } \\
\text { discapacidad }\end{array}$ & $\begin{array}{c}\text { Personas con } \\
\text { discapacidad }\end{array}$ & $\begin{array}{c}\text { Personas con } \\
\text { discapacidad } \\
\text { intelectual }\end{array}$ \\
\hline Tasa de actividad & 77,0 & 36,6 & 28,7 \\
\hline Tasa de empleo & 57,8 & 24,5 & 14,8 \\
\hline Tasa de paro & 25,0 & 33,1 & - \\
\hline
\end{tabular}

* Con certificado de discapacidad.

Fuente: Elaboración propia a partir de INE (2013).

Estos datos son una muestra elocuente de la baja participación en el mercado laboral, que se exacerba cuando se refieren al colectivo de PcDI, reduciéndose en cualquiera de los índices alrededor de 50 puntos respecto a la población ocupada sin discapacidad y casi io puntos respecto a las personas ocupadas con alguna discapacidad (INE, 20I3). De hecho, junto con las personas afectadas de trastorno mental, las PcDI obtienen los índices más bajos. Incluso, a pesar de que las PcDI han incrementado su tasa de actividad entre 20 I I y 20 I 2 prácticamente en I punto, su tasa de empleo se ha visto reducida en un $2,4 \%$ (I $7, \mathrm{I} \%$ en $20 \mathrm{II}$; I $4,7 \%$ en $20 \mathrm{I} 2)$.

Pensemos, por otra parte, que la inactividad y el desempleo tienen como causa no sólo la escasez de oferta, sino también en un alto porcentaje la falta de preparación profesional adecuada, como señala el Colectivo Ioé (20I2). Estos mismos autores indican que la mayoría de las personas con discapacidad que encuentran empleo lo hacen en el mercado ordinario de trabajo, a través de alguna de las fórmulas establecidas para facilitar su acceso a él, entre ellas, la cuota de reserva del $2 \%$ establecida por la legislación española en empresas con más de 50 empleados, los incentivos a la contratación o las bonificaciones en las cuotas de pago a la Seguridad Social, los empleos con apoyo, los enclaves laborales, etc. Los datos del INE (20I3) informan de que entre las y los ocupados con discapacidad, las PcDI son el colectivo con mayor porcentaje de personas con bonificación/ reducción en las cotizaciones $(34,7 \%)$. Es indispensable combatir "actitudes prejuiciosas e incorrectas que llevan a que apenas se haya conseguido la integración en el mercado laboral ordinario de las personas con discapacidad intelectual" (Valedor do Pobo ${ }^{3}, 2014$ : 228), instando a tomar las medidas legales precisas que eviten esta discriminación. Entre ellas, se señalan:

- La aplicación estricta de la vigente previsión legal de reserva y materialización de la cuota en los sectores público y privado, así como el incremento de inspecciones y sanciones por incumplimiento.

- La modificación de la cuota establecida, con el incremento del porcentaje de personas con discapacidad que han de contratar las empresas, una parte de ella reservada a PcDI.

- Promoción en los centros especiales de empleo de modelos de inserción laboral, mediante la transferencia de sus trabajadores a entornos laborales ordinarios, en la medida de lo posible.

- Continuar el desarrollo del empleo con apoyo como medio más adecuado para la integración social y laboral de las PcDI.

- Que el apoyo a la integración laboral no finalice con los programas formativos, sino que éstos se prolonguen en la labor de búsqueda de empleo.

3. El Valedor do Pobo es el alto comisionado del Parlamento de Galicia para la defensa de los derechos y libertades comprendidos en el Título I de la Constitución y en el estatuto de Autonomía de Galicia. Es una institución similar al Defensor del Pueblo, con funciones persuasivas y no coercitivas. 


\section{Evaluación y acreditación de competencias profesionales}

La Constitución Española (I978), en su artículo 40 , exige el fomento de la formación y la readaptación profesional para hacer realidad el derecho al trabajo. La cualificación profesional que proporciona esta formación eleva los niveles y la calidad de vida de las personas, además de favorecer la cohesión social y el fomento del empleo.

La Ley Orgánica 5/2002, de I9 de junio, de las Cualificaciones y de la Formación Profesional, entiende por Sistema Nacional de Cualificación y Formación Profesional:

"los instrumentos y acciones necesarias para desarrollar la integración de las ofertas de formación profesional, a través del Catálogo Nacional de Cualificaciones Profesionales, y la evaluación y acreditación de las correspondientes competencias profesionales, de forma que se favorezca el desarrollo profesional y social de las personas y se cubran las necesidades del sistema productivo".

En la misma normativa, se define cualificación profesional como el conjunto de competencias profesionales con significación para el empleo que se pueden adquirir mediante formación modular, otros tipos de formación o con la experiencia laboral. Las cualificaciones profesionales se recogen en el Catálogo Nacional de Cualificaciones Profesionales y se acreditan en títulos de Formación Profesional y certificados de profesionalidad. También se recoge la definición de competencia profesional de la Ley 5/2002, de I9 de junio, de las Cualificaciones y de la Formación Profesional, entendida como "el conjunto de conocimientos y capacidades que permitan el ejercicio de una actividad profesional conforme a las exigencias de la producción y el empleo".

Vemos, pues, que la noción de competencia, tal como se usa en relación al mundo del trabajo se sitúa a mitad de camino entre los saberes y las habilidades concretas (Bonsón, 2009); la competencia es inseparable de la acción, pero exige a la vez conocimiento. Puede entenderse entonces como un conjunto de propiedades en permanente modificación que deben ser sometidas a la prueba de la resolución de problemas concretos en situaciones de trabajo y que entrañan complejidad técnica.

Cerrillo e Izuzquiza (20I0) subrayan la ausencia de acuerdo en la definición del término, pero visualizan tres elementos comunes en las diferentes propuestas de conceptualización. El primero hace referencia al conjunto de conocimientos, actitudes y valores de la persona. El segundo elemento se refiere al conjunto de acciones que ponen en juego esos conocimientos, actitudes y valores; no basta con saber, también hay que saber hacer; por lo tanto, saber convertir en acciones el conocimiento es uno de los elementos esenciales del concepto de competencia. El tercer elemento para que ésta exista es que ese desempeño sea evaluable. Por lo tanto, la competencia sería el desempeño o la aplicación evaluable de conocimientos, actitudes y valores que Blas (2007: 42) concreta en "la aplicación de saberes que procura el logro de determinados resultados esperados conforme a las exigencias de la producción y el empleo”.

La competencia no proviene de la aprobación de un currículo escolar, sino de un ejercicio de aplicación de conocimientos en circunstancias concretas. De esta manera, como indica Struillou (2004), se reconoce que la actividad profesional de una persona produce competencias y conocimientos que se pueden aprender fuera de un sistema académico de formación.

Cabe destacar que no son patrimonio del puesto de trabajo, sino atributos de la persona trabajadora, e incorporan, consecuentemente, elementos individuales y sociales en una trayectoria que en cada caso es única. Esta individualización de las competencias llevó a la implementación de sistemas de evaluación coherentes con ella que permitiesen precisar qué resultados se esperan de una determinada acción o desempeño. En palabras de Blas (2007, 47), "un estándar de competencia constituye la 
expresión o definición operativa mínima de una competencia profesional”.

En los programas para la inserción laboral de PcDI, la fijación de estándares de competencia es una tarea especialmente importante, en la que hay que orientarse prioritariamente por dos referentes: por una parte, la motivación o razones de las empresas para contratar a PcDI; y por otra, los cometidos que van a asignarles en sus organizaciones. Según De Miguel y Cerrillo (20I0), para desarrollar adecuadamente competencias profesionales en jóvenes con discapacidad intelectual es necesario un equipo de profesionales que asuman y comprendan su rol de mediadores pedagógicos, que sean conscientes de la complejidad de su misión y que estén dotados de las herramientas necesarias para impulsar en los que aprenden el verdadero desarrollo de dichas competencias.

La acreditación de competencias debe tener tres características para ser útil en el mercado de trabajo:

- $\quad$ visibilidad, en el sentido de conocer cuáles son las habilidades concretas que esa acreditación indica;

- transferibilidad de un sector educacional a otro, de manera que las competencias adquiridas en el aprendizaje en el trabajo sirvan para continuar estudios en la Formación Profesional, así como que las habilidades adquiridas en la educación general, complementadas con conocimientos técnicos o práctica laboral, sirvan para la inserción en el mercado de trabajo; y

- $\quad$ transversalidad, de manera que puedan trasladarse de un tipo a otro de puesto de trabajo.

El Real Decreto I224/2009, del I7 de julio, de reconocimiento de las competencias profesionales adquiridas por experiencia laboral, establece el procedimiento de evaluación y acreditación que se guiará por los principios de respeto de los derechos individuales, fiabilidad, validez, objetividad, participación, calidad y coordinación.

La evaluación es el proceso estructurado de comprobación de la competencia profesional de una persona en las unidades de competencia del Catálogo Nacional de Cualificaciones Profesionales incluidas en títulos de Formación Profesional o certificados de profesionalidad. En dicho proceso, se toman como referentes las realizaciones profesionales (comportamientos esperados de la persona, objetivables por sus consecuencias o resultados), los criterios de realización (expresan el nivel aceptable de la realización profesional para satisfacer los objetivos de las organizaciones productivas) y el contexto profesional (define, con carácter orientador, los medios de producción, productos y resultados del trabajo, información utilizada o generada, y cuantos elementos similares se consideren necesarios para enmarcar la realización profesional).

La unidad de competencia es la unidad mínima susceptible de ser acreditada por la administración. El INCUAL determina para estas unidades de competencia cinco niveles de cualificación (de los que, hasta el momento, se han desarrollado los tres primeros), atendiendo a la competencia profesional requerida por las actividades productivas con arreglo a criterios de conocimientos, iniciativa, autonomía, responsabilidad y complejidad, entre otros, de la actividad a desarrollar.

Por lo tanto una competencia de nivel I, nivel de referencia del proceso de adaptación que aquí se expone, indica que la persona evaluada deberá ser competente en un conjunto de actividades simples dentro de procesos normalizados que son, en su mayoría, predecibles y rutinarios, con poca variedad en las operaciones. Entre ellas: aplicar procedimientos formalizados y predefinidos según normas y pautas establecidas, con pocas variables de control; tomar decisiones con un margen muy estrecho de alternativas, que son fácilmente reconocibles por sus consecuencias y que están limitadas a la elección de algunas variables. Generalmente los productos obtenidos requieren un trabajo de tipo colectivo, realizado 
bajo supervisión directa de ejecución. Este nivel implica unos conocimientos y capacidades limitadas (INCUAL, 20I4).

La Orden del I4 de enero de 20I4, por la que se convoca el proceso de acreditación de competencias profesionales adquiridas a través de la experiencia laboral en la comunidad autónoma de Galicia, desarrolla el procedimiento previsto a este fin (Real Decreto I 224/2009). El reconocimiento de competencias profesionales es un proceso complejo, que se estructura en tres fases: asesoramiento, fase en la que un asesor o asesora recopila todas las pruebas que se puedan aportar para demostrar la competencia profesional, y la persona candidata realiza un test de autoevaluación; la fase de evaluación de las competencias profesionales, en la que la comisión de evaluación utilizará los métodos que considere necesarios para comprobar lo expuesto en la documentación que se aporte en la fase anterior (observación directa en el puesto de trabajo, simulaciones, pruebas estandarizadas de competencia profesional o entrevista profesional); la acreditación y registro de las competencias es la última fase, a la que se llega tras la superación de la evaluación, y en ella se proporciona una acreditación de cada unidad en la que se haya demostrado la competencia profesional.

La Orden señala en su artículo 3 que, en Galicia, este proceso se realizará en centros integrados de Formación Profesional (CIFP) y establece que la evaluación será un proceso personalizado para cada persona candidata, dependiendo fundamentalmente de tres factores: el nivel de cualificación de la unidad de competencia, las características personales de la persona candidata y las evidencias de competencia indirectas aportadas por ella. Además destaca que a menor nivel, deben priorizarse los métodos de observación en una situación de trabajo real o simulado, mientras que, a niveles superiores, debe priorizarse la utilización de métodos indirectos, acompañados de entrevista profesional estructurada. La consideración de las características personales debe basarse en el principio de equidad, priorizándose la selección de aquellos métodos de carácter complementario que faciliten la generación de evidencias válidas.
Por ejemplo, nunca debe aplicarse una prueba de conocimientos de carácter escrito a un candidato de bajo nivel cultural en el que se aprecien dificultades de expresión escrita.

\section{La adaptación del proceso e instrumentos de evaluación de competencias a las características de PcDI}

Con el convencimiento de que la inserción laboral es un requisito para la inclusión social de las PcDI adultas, ya que aumenta su bienestar cuando tienen la posibilidad de desarrollar una participación plena en su entorno, como se establece en el artículo 27 de la Convención Internacional sobre los Derechos de las Personas con Discapacidad, se procedió a la realización adaptada del proceso de evaluación de una unidad de competencia de nivel I identificada por el Instituto Nacional de las Cualificaciones Profesionales, con el objetivo de determinar la capacidad de desempeño del perfil profesional de operaciones básicas de montaje del alumnado con discapacidad intelectual de un centro ocupacional.

La dificultad de incorporación laboral de las PcDI, que viene denunciándose reiteradamente (Valedor do Pobo, 20I4), tiene en la insuficiencia de medidas de fomento del empleo una de sus principales causalidades. En vistas a la mejora de esta situación, se apunta como uno de los principales objetivos de la ejecución de los denominados ajustes razonables, tales como la adaptación de instalaciones, equipamientos, pautas de trabajo, asignación de funciones o provisión de medios de formación recogidos en la Directiva europea $2000 / 78$ relativa al establecimiento de un marco general para la igualdad de trato en el empleo y la ocupación. En este sentido, la adaptación del proceso y los instrumentos de evaluación de competencias puede interpretarse como un ajuste razonable previo que mejoraría las posibilidades de inserción de estas personas en el mercado laboral ordinario. 


\subsection{Contexto de actuación}

La intervención socioeducativa que describimos se desarrolló en el centro ocupacional para PcDI que la Asociación AMIPA gestiona en la Comarca do Sar (A Coruña). O Sar, con una población aproximada de $\mathrm{I} 6.800$ habitantes, es un territorio eminentemente rural próximo a Santiago de Compostela, formado por los municipios de Dodro, Rois y Padrón, siendo la villa de Padrón el núcleo urbano de mayor entidad de la zona.

Cabe destacar la alta prevalencia de PcDI en la comarca $(0,79 \%)$, en comparación con los datos de Galicia (0,37\%) y del Estado español $(0,38 \%)$, como se puede observar en la Tabla 2. Esta circunstancia es especialmente destacable teniendo en cuenta que en el contexto de actuación en el que se desarrolló la intervención no existe ningún otro servicio específico ni recurso próximo para este colectivo que no sea el centro ocupacional de AMIPA.
Es importante destacar la fuerte implantación en la Comarca do Sar de multitud de empresas relacionadas con el sector del aluminio. En 20ıо, el Instituto Galego de Estatística (2OI4) registraba en la zona 3 I empresas de "fabricación de elementos metálicos para la construcción”, entre ellas, alguna multinacional con gran número de empleados. De ahí la oportunidad del Programa de Transición a la Vida Adulta de las Personas con Discapacidad Intelectual ofrecido por AMIPA, en el que se planificó la realización de una Acción Formativa de Montaje de Accesorios y Complementos de Aluminio dirigida a ocho PcDI y que constituyó el marco en el que se llevó a cabo la evaluación que se propone en este estudio.

Por otra parte, en el período 2006-20I 2, según datos del Instituto Galego das Cualificacións (20I4), la ocupabilidad laboral fue muy alta, con una tendencia de crecimiento relevante en el sector. De hecho, como se muestra en la Tabla 3, las contrataciones del perfil de peón de las

\section{Tabla 2. Demografía y prevalencia de PcDI en la Comarca do Sar (comparativa)}

\begin{tabular}{|l|c|c|c|}
\hline & Habitantes & PcDI* $^{*}$ & \% \\
\hline Dodro & 2.980 & 23 & 0,77 \\
\hline Padrón & 8.924 & 77 & 0,86 \\
\hline Rois & 4.910 & 33 & 0,67 \\
\hline Total Comarca do Sar & 16814 & 133 & 0,79 \\
\hline Galicia & 2.772 .928 & 10.200 & 0,37 \\
\hline España & 46.815 .916 & 177.300 & 0,38 \\
\hline
\end{tabular}

* La columna recoge los datos estadísticos de personas con certificado de discapacidad. En los datos facilitados por los ayuntamientos de la Comarca do Sar, se computa la categoría "personas con disminución psíquica” en terminología del Servicio Informático de Usuarios de Servicios Sociales (SIUSS). Los datos de Galicia y España recogen la categoría "personas con discapacidad intelectual” utilizada en INE (2OI3).

Fuente: Elaboración propia a partir de INE (2OI I, 20I3) y datos facilitados por los servicios sociales de los Ayuntamientos de la Comarca do Sar.

Tabla 3. Contrataciones de peones de las industrias manufactureras. O Sar, 2006-2012

\begin{tabular}{|l|c|c|c|c|c|c|c|}
\hline & $\mathbf{2 0 0 6}$ & $\mathbf{2 0 0 7}$ & $\mathbf{2 0 0 8}$ & $\mathbf{2 0 0 9}$ & $\mathbf{2 0 1 0}$ & $\mathbf{2 0 1 1}$ & $\mathbf{2 0 1 2}$ \\
\hline $\mathrm{N}^{\circ}$ contrataciones & 838 & 719 & 533 & 488 & 506 & 389 & 349 \\
\hline \% sobre el total & 26,54 & 23,96 & 20,42 & 18,83 & 20,05 & - & - \\
\hline
\end{tabular}

Fuente: Elaboración propia a partir de Instituto Galego das Cualificacións (20I4). 
industrias manufactureras, ocupación y puesto de trabajo relevante en la cualificación profesional a la que pertenece la unidad de competencia que se evaluará en este trabajo, prácticamente superaron en el período 2006-2010 el $20 \%$ del total de contrataciones en la comarca. Las posibilidades reales de inserción laboral en este sector refuerza la necesidad de conocer la preparación para este perfil laboral de las PcDI.

\subsection{El Centro Ocupacional de Sorribas (Rois) y la evaluación de competencias}

El trabajo consistió en la evaluación de la competencia profesional del grupo de PcDI que había estado recibiendo formación para el empleo a través de la Acción Formativa de Montaje de Accesorios y Complementos de Aluminio. Es precisamente la superación de esta formación la que permite que las personas participantes obtengan todos los requisitos legales previstos para presentarse a la acreditación oficial de la experiencia profesional en competencias de nivel I: haber realizado al menos 200 horas de formación relacionada con la competencia profesional a acreditar, tener nacionalidad española, tener más de 18 años y no estar matriculado en ningún curso de Formación Profesional inicial.

El objetivo de evaluar competencias es habitualmente acreditarlas. En este caso, el proceso fue previo a una acreditación formal, dado que el objetivo era comprobar si las PcDI estaban o no preparadas para llevar a cabo el desempeño profesional para el que habían sido formadas.

En el caso de obtener una evaluación positiva, las PcDI serían orientadas hacia un itinerario de inserción laboral, a la espera de que esta unidad de competencia se acredite oficialmente en Galicia, hecho que no se produce en este momento. De no superar la evaluación de competencias la PcDI, podrían ser orientadas, en función del resultado, hacia:

- Continuar en el centro ocupacional, incorporándose a las actividades rutinarias.
- Realizar una nueva formación como montadores/as.

- Incorporarse a un eventual centro especial de empleo que la Asociación pudiera crear si hubiese un grupo de personas que, sin superar la evaluación, pudiesen desempeñar este perfil.

- El empleo con apoyo: esta opción estaría limitada a PcDI que no superaran la evaluación, pero hubiesen demostrado una capacidad de desempeño considerable en la evaluación.

Por ello, además del proceso de evaluación que a continuación se expone, también se comprobó la necesidad de apoyo de la PcDI en el momento de desarrollar las diferentes actividades de evaluación, lo que ayudaría a posteriori a definir un itinerario de orientación e inserción laboral.

\subsection{Identificación de la cualificación profesional de la unidad de competencia evaluada}

En el Cuadro I, se muestra la cualificación profesional de operaciones auxiliares de fabricación mecánica, del Catálogo Nacional de Cualificaciones Profesionales.

La unidad de competencia evaluada pertenece a la cualificación profesional de operaciones auxiliares de fabricación mecánica de nivel I del INCUAL. En el Cuadro 2, se exponen las realizaciones profesionales y criterios de realización previstos con carácter general, y que serán referentes para el diseño de los instrumentos adaptados de evaluación propuestos en este trabajo.

\subsection{Metodología: el "saber haciendo"}

Como se ha señalado, la evaluación basada en la competencia consiste fundamentalmente en la acumulación de suficientes pruebas de evidencia que permitan inferir con toda confianza la competencia de la persona candidata a ser acreditada. Las competencias técnicas se desglosan 


\section{Cuadro 1. Cualificación profesional de operaciones auxiliares de fabricación mecánica}

\begin{tabular}{|l|l|}
\hline \multicolumn{2}{|l|}{ Familia profesional: fabricación mecánica } \\
\hline Cualificación profesional: operaciones auxiliares de fabricación mecánica (nivel 1) \\
\hline \multirow{2}{*}{ Competencia general } & $\begin{array}{l}\text { Realizar operaciones básicas de fabricación, así como alimentar y asistir los procesos de mecanizado, montaje } \\
\text { y fundición automatizados, con criterios de calidad, seguridad y respeto al medio ambiente. }\end{array}$ \\
\hline \multirow{2}{*}{$\begin{array}{l}\text { Unidades de } \\
\text { competencia (UC) }\end{array}$} & UC1. Realizar operaciones básicas de fabricación. \\
\cline { 2 - 2 } Ámbito profesional & $\begin{array}{l}\text { Uesempeña su actividad laboral en grandes, medianas y pequeñas empresas dedicadas a la fabricación } \\
\text { y montaje de productos mecánicos. Opera siguiendo instrucciones de técnicos superiores y según } \\
\text { procedimientos establecidos. }\end{array}$ \\
\hline \multirow{2}{*}{$\begin{array}{l}\text { Sectores productivos } \\
\text { Ocupaciones básicas de montaje. }\end{array}$} & $\begin{array}{l}\text { Fabricación de productos electromecánicos, talleres mecánicos, construcción de maquinaria, construcción y } \\
\text { construcción de bicicletas y motocicletas, así como fabricación de otro material de transporte. }\end{array}$ \\
\hline de trabajo relevantes
\end{tabular}

Fuente: Elaboración propia a partir de INCUAL (2014).

\section{Cuadro 2. Unidad de competencia 2: realizar operaciones básicas de montaje}

\section{Cualificación profesional: operaciones auxiliares de fabricación mecánica (nivel 1)}

Unidad de competencia 2: realizar operaciones básicas de montaje

RP1: Preparar materiales, maquinaria y elementos necesarios para la realización de uniones, aplicando las normas de prevención de riesgos laborales y medio ambiente.

RP2: Unir piezas con elementos desmontables o mediante adhesivos, aplicando las normas de prevención de riesgos laborales y medio ambiente.

RP3: Verificar las uniones realizadas, utilizando los instrumentos básicos de medida y control.

CR1.1. Los planos y especificaciones técnicas se interpretan según las normas de representación gráfica.

CR1.2. Las zonas de trabajo de su responsabilidad permanecen en condiciones de limpieza, orden y seguridad.

CR1.3. Los medios, herramientas y equipos que se van a emplear se mantienen en las condiciones de uso establecidas.

CR1.4. Las máquinas y herramientas se preparan según procedimientos y parámetros establecidos.

CR2.1. Los medios a utilizar son seleccionados en función de la operación a realizar.

CR2.2. Los montajes son realizados según las instrucciones recibidas y garantizan las especificaciones de unión.

CR2.3. Las herramientas y la maquinaria del taller, una vez usadas, se limpian y se almacenan teniendo en cuenta las condiciones de mantenimiento.

CR3.1. Las superficies que deben verificarse están limpias y exentas de rebabas.

CR3.2. Los instrumentos de verificación están calibrados para su uso.

CR3.3. La verificación se realiza siguiendo procedimientos establecidos.

CR3.4. El montaje se valida en función de la verificación realizada.

\section{Contexto profesional}

- Medios de producción: aparatos de elevación y transporte, remachadoras, herramientas y útiles de montaje, adhesivos, instrumentos de verificación.

- Productos y resultados: conjuntos unidos por tornillos, remaches, adhesivos, piezas soldadas por resistencia, etc.

- Información utilizada o generada: planos constructivos y de detalle, normas de prevención de riesgos laborales y medio ambiente, especificaciones de montaje, instrucciones de uso de adhesivos, procedimientos de metrología.

RP: realizaciones profesionales. CR: criterios de realización.

Fuente: Elaboración propia a partir de INCUAL (20I4). 
en "saber" y "saber hacer", mientras que las sociales consisten en "saber estar". Este conjunto de saberes constituyen las tres dimensiones clásicas de la competencia profesional:

- La dimensión de la competencia relacionada con el "saber", comprende el conjunto de conocimientos conceptuales y procedimentales de carácter técnico.

- La dimensión relacionada con el "saber hacer" aparece explicitada en forma de actividades que se extraen de las realizaciones profesionales y de los criterios de realización.

- La dimensión de la competencia relacionada con el "saber estar" examina capacidades de tipo actitudinal extraídas de las correspondientes realizaciones profesionales y criterios de realización de la unidad de competencia.

Las PcDI son un colectivo que sufre la inadecuación de métodos de evaluación en pruebas estandarizadas, lo que las lleva a fracasar en procesos que no se adaptan a sus características. Creemos que tanto las propuestas del INCUAL como la legislación vigente en la materia abren la puerta a la realización de adaptaciones en la metodología para adaptarla a las características de las personas candidatas a ser acreditadas en competencias profesionales, e incluso exigen a la persona evaluadora que lleve a cabo dichas adaptaciones.

Por ello, proponemos una reconceptualización de las dos primeras dimensiones en lo que hemos denominado "saber haciendo". Si somos competentes cuando somos capaces de hacer, como señalan De Miguel y Cerrillo (20I0), éste debe ser el criterio de evaluación aplicado, toda vez que los métodos tradicionales de evaluación son frecuentemente inalcanzables para las PcDI.

Se trata, en definitiva, de hacer efectivo el derecho a la igualdad de oportunidades de las personas con discapacidad, poniendo en marcha medidas de acción positiva orientadas a compensar las desventajas para participar plenamente en la vida laboral, social y cultural, de acuerdo con los principios de normalización y autodeterminación, como han señalado Becerra et al. (2008). En este sentido, en el proceso de adaptación que describimos se prevén cinco categorías de apoyo, de menor a mayor intensidad, cuyas características se recogen en el Cuadro 3.

Siguiendo la metodología e instrumentos INCUAL, así como la legislación vigente, la responsabilidad de llevar a cabo la evaluación fue un proceso compartido entre quien diseñó el instrumento y una persona que cumplía los requisitos definidos en el Real Decreto

Cuadro 3. Previsión de apoyos durante el proceso de evaluación adaptada

\begin{tabular}{|l|l|c|}
\hline Apoyos & Descripción & Intensidad \\
\hline Físico & $\begin{array}{l}\text { Es la máxima proporción de ayuda que necesita una persona para } \\
\text { completar una tarea. Exige que el formador tome las manos del } \\
\text { candidato a la acreditación y acompañe el modo de realizar la tarea. }\end{array}$ & \\
\hline Verbal & $\begin{array}{l}\text { Consisten en instrucciones sobre el desarrollo de la tarea dadas de } \\
\text { palabra. }\end{array}$ & $\begin{array}{l}\text { Son indicaciones no verbales que ayudan a comprender lo que debe } \\
\text { hacerse en la tarea. }\end{array}$ \\
\hline Gestual & $\begin{array}{l}\text { Consiste en hacer una demostración donde se vean las acciones } \\
\text { que se deben ejecutar. }\end{array}$ & $\begin{array}{l}\text { Son apoyos no personales (gráficos, esquemas, secuencias) que } \\
\text { permiten conocer el desarrollo de una tarea. }\end{array}$ \\
\hline Instrumental & &
\end{tabular}

Fuente: Elaboración propia a partir de Marset (200I). 
I224/2009, del I7 de julio, de reconocimiento de las competencias profesionales adquiridas por experiencia laboral, para poder asesorar y evaluar competencias profesionales, en este caso, en operaciones auxiliares de fabricación mecánica - operaciones básicas de montaje. Así, el formador para el empleo que impartió la acción formativa en el centro colaboró de manera imprescindible en la parte técnica del proceso evaluador llevado a cabo.

Los métodos e instrumentos de evaluación de la unidad de competencia se fundamentaron en los requisitos de fiabilidad, validez y eficacia, entendidos en los siguientes términos:

- Validez: los métodos de evaluación empleados para la obtención de evidencias deben medir la competencia profesional fijada por el referente de evaluación.

- Fiabilidad: consiste en la estabilidad de los resultados medidos con el mismo método o instrumento. Un método o instrumento es fiable en la medida en que los resultados son comparables y homogéneos en todos los participantes, independientemente de quien efectúe la evaluación.

- Eficacia: un instrumento es considerado eficaz cuando nos permite alcanzar los objetivos propuestos, es decir, la evaluación de la competencia profesional de la persona candidata en coherencia con el referente de evaluación.

El proceso se desarrolló siguiendo un marco flexible basado en situaciones profesionales de evaluación, utilizándose para la valoración criterios de mérito, indicadores y escalas de desempeño competente. La propuesta prevé que si el formato de la propia evaluación supusiese un obstáculo en la demostración de competencia por parte de la PcDI, se irían incorporando los apoyos previstos, ofreciendo de esta manera, en palabras de Albert (2006), un entorno de confianza y cooperación a los actores participantes.

Las actividades de evaluación recogieron evidencias de competencia acerca de la capacidad del candidato para integrar conocimientos, habilidades y actitudes; es decir, que nos permitieron evaluar la competencia profesional de forma integrada. Para ello, se pusieron en práctica las siguientes actividades de evaluación:

- Observación. El objetivo principal era recoger información de la persona candidata por medio de indicadores predefinidos. La observación del desarrollo profesional debe tomar como referente las realizaciones profesionales y los criterios de realización de la unidad de competencia, junto con su contexto profesional.

- Simulaciones de actividades profesionales: son situaciones de evaluación (en taller, laboratorio o empresa) en las que se diseñan y reconstruyen las variables principales de una actuación profesional, cuyo dominio por parte de una persona candidata se pretende verificar. Responden, en su mayor parte, a una serie de ejercicios prácticos que se elaboran para evaluar las competencias profesionales que se quieren verificar.

Las evaluaciones de competencias se deben llevar a cabo, siempre que sea posible, en el entorno laboral al que pertenece la persona candidata. En este caso, se desarrolló a través de lo que el INCUAL (20I4) denomina "simulación de situación profesional de evaluación”, concretamente de la unidad de competencia "realizar operaciones básicas de montaje". La situación profesional de evaluación para esta unidad de competencia es descrita por el organismo oficial en los siguientes términos:

"La persona candidata demostrará la competencia requerida para montar uno o varios conjuntos de piezas metálicas que contengan elementos deslizantes lineales o giratorios, y uniones desmontables y fijas, partiendo del plano o planos de conjunto y utilizando las herramientas, útiles y materiales de unión específicos para las operaciones de montaje, cumpliendo las normas de prevención de riesgos laborales y medio ambientales aplicables". 
Esta situación profesional de evaluación abarcará las siguientes actividades:

- Selección de herramientas, materiales y útiles de montaje.

- Preparación de las superficies a ensamblar.

- Ejecución de las operaciones de montaje y ensamblado.

- Comprobación dimensional y funcional del montaje.

\subsection{Instrumentos de evaluación}

Para desarrollar el proceso, se adaptaron dos instrumentos: el primero, para comprobar de manera holística la competencia de la persona evaluada en lo referente a conceptos y procedimientos (lo que hemos denominado "saber haciendo"); el segundo, para la recogida del desempeño actitudinal. Ambos toman como referente los criterios de realización expresados en las realizaciones profesionales que se contemplan en la unidad de competencia (Cuadro 2), considerando el contexto expresado en la situación profesional de evaluación.

El primer instrumento contempla los requerimientos del nivel de desempeño para cada criterio de mérito relacionado con el "saber" y el "saber hacer" de las escalas de desempeño competente que acompañan a un registro donde se plasmará la observación realizada. La evaluación positiva implica lograr los cinco umbrales de competencia.

En los Cuadros 5 a 9, se muestran las escalas de desempeño competente de la unidad de competencia relacionadas con el "saber haciendo" (criterios de mérito, indicadores y umbrales de desempeño competente).

\section{Cuadro 4. Instrumento para la evaluación del "saber haciendo"}

\begin{tabular}{|c|c|c|c|c|c|c|}
\hline \multicolumn{7}{|l|}{ Nombre de la persona evaluada: } \\
\hline \multicolumn{7}{|l|}{ Evaluador: } \\
\hline \multicolumn{7}{|l|}{ Fecha de evaluación: } \\
\hline \multicolumn{7}{|l|}{ Unidad de competencia evaluada: } \\
\hline \multirow{2}{*}{$\begin{array}{l}\text { Grado de cumplimiento de los criterios de } \\
\text { mérito (CM) relacionados con el "saber } \\
\text { haciendo" }\end{array}$} & \multicolumn{3}{|c|}{$\begin{array}{l}\text { Logra el umbral de } \\
\text { desempeño competente }\end{array}$} & \multicolumn{2}{|c|}{$\begin{array}{l}\text { Necesidad } \\
\text { de apoyo o } \\
\text { adaptación }\end{array}$} & \multirow{2}{*}{$\begin{array}{l}\text { Descripción } \\
\text { del apoyo } \\
\text { recibido }\end{array}$} \\
\hline & Sí & No & $\begin{array}{l}\text { Nivel } \\
\text { logrado }\end{array}$ & Sí & No & \\
\hline \multicolumn{7}{|l|}{$\begin{array}{l}\text { CM1. Orden y limpieza de herramientas, } \\
\text { materiales y útiles de montaje }\end{array}$} \\
\hline \multicolumn{7}{|l|}{$\begin{array}{l}\text { CM2. Preparación de las superficies a } \\
\text { ensamblar }\end{array}$} \\
\hline \multicolumn{7}{|l|}{$\begin{array}{l}\text { CM3. Ejecución de las operaciones de } \\
\text { montaje y ensamblado }\end{array}$} \\
\hline \multicolumn{7}{|l|}{$\begin{array}{l}\text { CM4. Comprobación dimensional y funcional } \\
\text { del montaje }\end{array}$} \\
\hline $\begin{array}{l}\text { CM5. Desarrollar las actividades cumpliendo } \\
\text { las normas de prevención de riesgos } \\
\text { laborales y protección del medio ambiente } \\
\text { aplicables }\end{array}$ & & & & & & \\
\hline
\end{tabular}

Fuente: Elaboración propia. 

propuesta de adaptación de la metodología e instrumentos INCUAL para la igualdad de oportunidades

\section{Cuadro 5. Criterio de mérito 1 para la evaluación del "saber haciendo"}

\section{Criterio de mérito 1: orden y limpieza de materiales, herramientas y útiles de montaje}

Indicadores:

- La limpieza y orden de las herramientas y útiles de montaje.

- Los útiles y herramientas seleccionadas se encuentran en estado operativo y sin daños.

- Los materiales seleccionados se encuentran sin desperfectos.

\section{Escala de desempeño competente}

$1 \quad$ El puesto de trabajo, las herramientas y los útiles están sucios y desordenados.

2 El puesto de trabajo, las herramientas y los útiles están sucios durante el montaje.

3 El puesto de trabajo, las herramientas y los útiles están desordenados al finalizar el montaje.

$4 \quad$ El puesto de trabajo, las herramientas y los útiles están mayoritariamente limpios y ordenados.

5 El puesto de trabajo, herramientas y los útiles utilizados en el montaje se encuentran limpios, bien mantenidos y ordenados en todo momento.

El umbral de desempeño competente: número 4 de la escala.

Fuente: Elaboración propia a partir de INCUAL (20I4).

\section{Cuadro 6. Criterio de mérito 2 para la evaluación del "saber haciendo"}

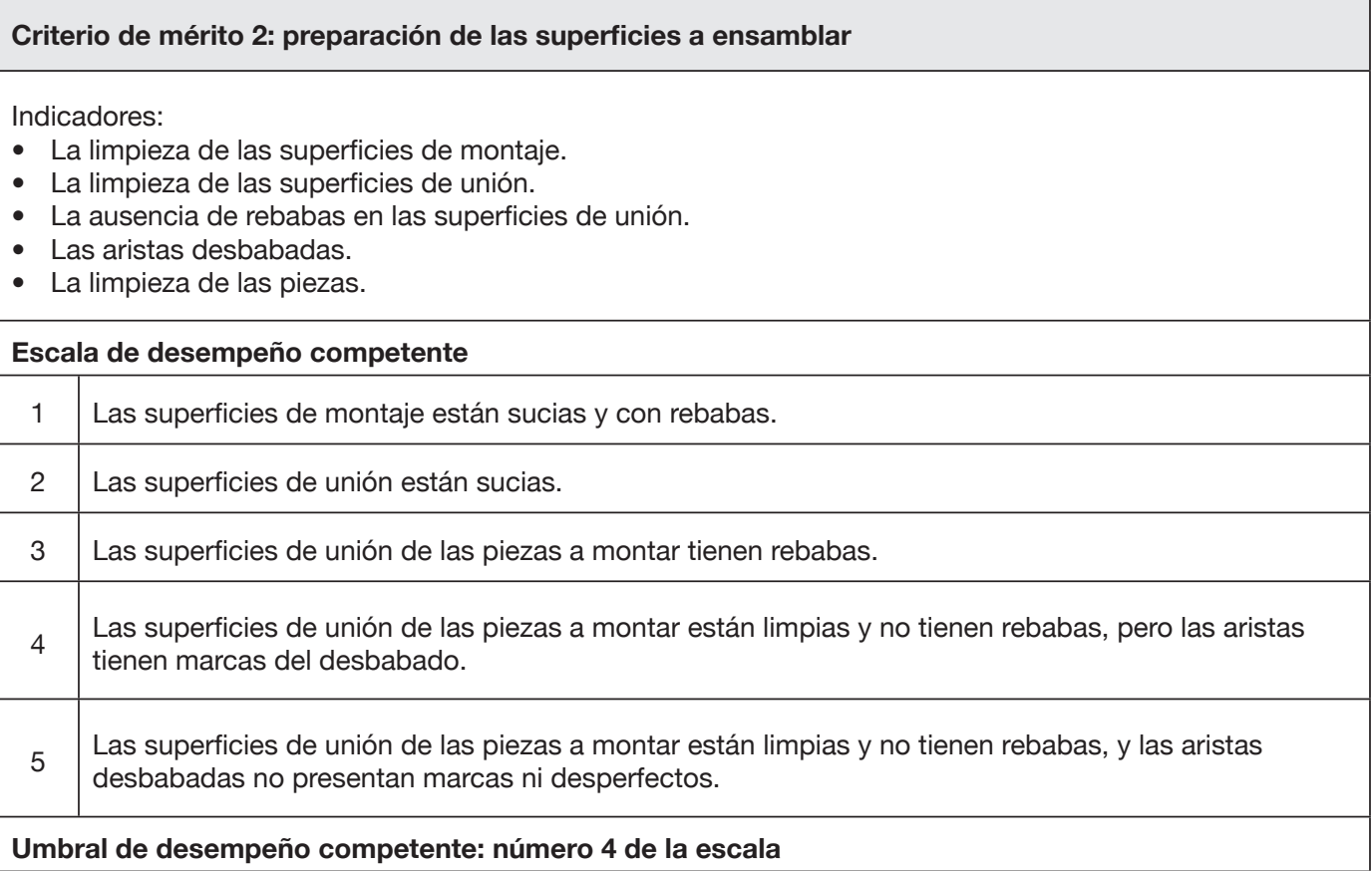

Fuente: Elaboración propia a partir de INCUAL (20I4). 


\section{Cuadro 7. Criterio de mérito 3 para la evaluación del "saber haciendo"}

\begin{tabular}{|l|l|}
\hline Criterio de mérito 3: ejecución de las operaciones de montaje y ensamblado \\
\hline $\begin{array}{l}\text { Indicadores: } \\
\text { - La secuencia de operaciones de montaje. } \\
\text { - Las herramientas y materiales utilizados en el montaje. } \\
\text { - El tiempo empleado en el montaje. }\end{array}$ \\
\hline Escala de desempeño competente \\
\hline 1 & No se montó el conjunto de piezas. \\
\hline 2 & $\begin{array}{l}\text { El conjunto montado no responde a las especificaciones funcionales, porque no se realizó el proceso } \\
\text { especificado. }\end{array}$ \\
\hline 3 & $\begin{array}{l}\text { El conjunto montado responde parcialmente a las especificaciones del plano, pero se siguió el } \\
\text { procedimiento especificado en la hoja de proceso y se terminó en el tiempo establecido. }\end{array}$ \\
\hline 4 & El conjunto montado responde a lo especificado en el plano, pero no se siguió el proceso descrito. \\
\hline 5 & $\begin{array}{l}\text { El conjunto montado responde a lo especificado en el plano y se realizó con las herramientas } \\
\text { especificadas en la hoja de proceso, y aquéllas se utilizaron según las especificaciones de uso. }\end{array}$ \\
\hline El umbral de desempeño competente: número 3 de la escala. \\
\hline
\end{tabular}

El umbral de desempeño competente: número 3 de la escala.

Fuente: Elaboración propia a partir de INCUAL (20I4).

\section{Cuadro 8. Criterio de mérito 4 para la evaluación del "saber haciendo"}

\section{Criterio de mérito 4: comprobación dimensional y funcional del montaje}

Indicadores:

- El uso de los instrumentos de medida y control.

- Las mediciones dimensionales.

- El desplazamiento de los elementos deslizantes.

- La resistencia de las uniones tiene la solidez adecuada.

\section{Escala de desempeño competente}

\begin{tabular}{|c|l|}
\hline 1 & No se utilizan los instrumentos de medición. \\
\hline 2 & Los instrumentos utilizados no son adecuados para la magnitud a medir. \\
\hline 3 & $\begin{array}{l}\text { Se miden las cotas significativas relativas al montaje, especificadas en el plano, con los instrumentos } \\
\text { adecuados a la magnitud a medir y la precisión requerida, pero no se siguen los procedimientos } \\
\text { establecidos. }\end{array}$ \\
\hline 4 & $\begin{array}{l}\text { Se miden las cotas significativas relativas al montaje, especificadas en el plano, según } \\
\text { procedimientos establecidos con los instrumentos adecuados a la magnitud a medir y la precisión } \\
\text { requerida. }\end{array}$ \\
\hline 5 & $\begin{array}{l}\text { Se miden todas las cotas relativas al montaje especificadas en el plano según procedimientos } \\
\text { establecidos, con los instrumentos adecuados a la magnitud a medir y a la precisión requerida. }\end{array}$ \\
\hline
\end{tabular}

Fuente: Elaboración propia a partir de INCUAL (20I4). 
Criterio de mérito 5: desarrollar las actividades cumpliendo las normas de prevención de riesgos laborales aplicables y de protección del medio ambiente

Indicadores:

- Las actividades de montaje cumplen con las normas de prevención de riesgos laborales.

- Las actividades de montaje cumplen con las normas de protección del medio ambiente.

\section{Escala de desempeño competente}

1 Se cumple con las normas de prevención de riesgos laborales.

2 Se cumple con las normas de protección del medio ambiente.

Se requiere el cumplimiento total de este criterio en todas las actividades.

Fuente: Elaboración propia a partir de INCUAL (20I4).

El segundo instrumento especifica los requisitos del nivel de desempeño relacionados con el "saber estar". En este caso, el resultado de la evaluación de la competencia profesional puede adquirir tres valores: una valoración positiva, una valoración negativa, o se puede lograr el nivel de competencia con necesidad de apoyo.

La evaluación actitudinal se realizará en dos tipos de situación: trabajo sin interacción interpersonal y trabajo con interacción interpersonal. En el primer caso, se realizará simultáneamente a la evaluación de los procedimientos. Para la segunda situación, se tomará como referencia la evaluación continua realizada a lo largo de las sesiones de la acción formativa desarrollada en el centro ocupacional.

La metodología INCUAL no define un umbral de competencia en relación a los indicadores utilizados en la observación del desempeño actitudinal, limitándose a indicar que la persona candidata debe demostrar "la posesión de actitudes" de comportamiento en el trabajo. Por consiguiente, se estableció, con el asesoramiento del profesional experto en la unidad de competencia especificada que actuaría como evaluador, el umbral de superación de diez de los indicadores señalados para conseguir una evaluación positiva de la competencia profesional (Cuadro Io).
Una vez diseñados los instrumentos de evaluación, y antes de su aplicación, se llevó a cabo una reunión con el formador para acordar la metodología a seguir: aspectos técnicos del proceso evaluador, medios y materiales precisos, y características del procedimiento. También se abordó la previsión de apoyos para la evaluación, en el sentido de que, en un primer momento, se debía procurar que la persona evaluada llevase a cabo las tareas sin apoyos, y en el caso de ser precisos, aplicarlos pautadamente para comprobar si la persona evaluada conseguía realizar la tarea.

En el transcurso de la reunión, se informó de la decisión de evaluar sólo a dos de las personas asistentes al centro ocupacional, a fin de interrumpir lo menos posible su actividad cotidiana. La evaluación se llevó a cabo con dos alumnos seleccionados por el formador atendiendo a los siguientes criterios: uno de ellos, por tener posibilidades reales de superar la evaluación de la competencia profesional, lo que demostraría la posibilidad de inserción laboral basada en la capacidad laboral que sin este proceso se le niega; la otra persona fue escogida al azar entre el resto de participantes, sin que existiera una previsión sobre la respuesta ante este tipo de prueba. De esta forma, participaron un alumno y una alumna con las siguientes características: el alumno, de 48 años, 


\begin{tabular}{|c|c|c|c|c|c|}
\hline \multicolumn{6}{|c|}{ Cuadro 10. Instrumento para la evaluación del "saber estar" } \\
\hline \multicolumn{6}{|c|}{ Nombre de la persona evaluada: } \\
\hline \multicolumn{6}{|c|}{ Evaluador: } \\
\hline \multicolumn{6}{|c|}{ Fecha de evaluación: } \\
\hline \multicolumn{6}{|c|}{ Unidad de competencia evaluada: } \\
\hline \multirow{2}{*}{$\mathbf{N}^{\circ}$} & \multirow{2}{*}{ Indicadores } & \multicolumn{3}{|c|}{$\begin{array}{l}\text { Logra el nivel de } \\
\text { competencia }\end{array}$} & \multirow{2}{*}{$\begin{array}{l}\text { Tipo de apoyo } \\
\text { proporcionado }\end{array}$} \\
\hline & & Sí & No & Con apoyo & \\
\hline 1 & Mantiene una actitud tolerante y de respeto. & & & & \\
\hline 2 & $\begin{array}{l}\text { Es tolerante ante las actuaciones y actitudes } \\
\text { discrepantes. }\end{array}$ & & & & \\
\hline 3 & Se preocupa por mejorar activamente en el trabajo. & & & & \\
\hline 4 & $\begin{array}{l}\text { Muestra responsabilidad en el trabajo individual y en } \\
\text { equipo. }\end{array}$ & & & & \\
\hline 5 & $\begin{array}{l}\text { Muestra iniciativa en la búsqueda de soluciones y en } \\
\text { la resolución de problemas. }\end{array}$ & & & & \\
\hline 6 & $\begin{array}{l}\text { Participa y colabora activamente con sus superiores, } \\
\text { avisando puntualmente de las incidencias. }\end{array}$ & & & & \\
\hline 7 & $\begin{array}{l}\text { Es diligente en la interpretación y ejecución de las } \\
\text { instrucciones recibidas. }\end{array}$ & & & & \\
\hline 8 & $\begin{array}{l}\text { Transmite diligentemente la información generada a } \\
\text { la persona responsable. }\end{array}$ & & & & \\
\hline 9 & Propone mejoras en los procesos de trabajo. & & & & \\
\hline 10 & $\begin{array}{l}\text { Se comunica eficaz y fluidamente con sus } \\
\text { superiores. }\end{array}$ & & & & \\
\hline 11 & Cuida el aspecto y aseo personal como profesional. & & & & \\
\hline 12 & $\begin{array}{l}\text { Cumple las normas de comportamiento profesional: } \\
\text { puntualidad, orden, limpieza. }\end{array}$ & & & & \\
\hline 13 & Distingue entre ámbito profesional y personal. & & & & \\
\hline 14 & $\begin{array}{l}\text { Cumple el plan de prevención y las normas de } \\
\text { seguridad e higiene laboral. }\end{array}$ & & & & \\
\hline 15 & $\begin{array}{l}\text { Mantiene una actitud preventiva de vigilancia } \\
\text { periódica del estado de su salud ante los riesgos } \\
\text { laborales. }\end{array}$ & & & & \\
\hline
\end{tabular}

Fuente: Elaboración propia a partir de INCUAL (20I4).

con necesidad de apoyo intermitente, valorado con "retraso mental leve" ${ }_{4}$ y un grado de discapacidad del $66 \%$; la alumna, de 36 años, con necesidad de apoyo intermitente, valorada con "retraso mental moderado" y grado de discapacidad del $67 \%$.

4. Esta terminología responde a la literalidad de los certificados de discapacidad en los que se establece el reconocimiento de la discapacidad intelectual de las personas evaluadas.

\section{Resultados de la evaluación}

Como se mencionó con anterioridad, la evaluación conceptual se adaptó, integrándose en la evaluación procedimental ("saber haciendo"), y consistió en la simulación de actividades profesionales que requerían: 
- La selección de herramientas, materiales y útiles de montaje.

- La preparación de las superficies a ensamblar.

- La ejecución de las operaciones de montaje y ensamblado.

- La comprobación dimensional y funcional del montaje.

Al mismo tiempo, se procedió a evaluar el desempeño actitudinal en aquellas tareas que no contemplaban la interacción interpersonal. Para la evaluación de las actitudes en momentos de interacción con otras personas, se tomó como referencia la evaluación continua realizada por el formador a lo largo de las sesiones de la acción formativa desarrollada en el centro ocupacional.

\subsection{Resultados de la evaluación del alumnado}

El alumno obtuvo unos resultados muy favorables en la simulación de actividades profesionales, logrando el nivel de desempeño competente en las cinco escalas relacionadas con el "saber haciendo" (Cuadros 5 a 9), alcanzando incluso resultados por encima del umbral de competencia en el criterio de mérito 3 (Cuadro 7). Estos resultados fueron conseguidos sin necesidad de apoyo (Cuadro 3 ) por parte del evaluador.

Los resultados relativos al desempeño actitudinal "saber estar" (Cuadro Io) fueron igualmente favorables, tanto en situaciones de interacción con otras personas como en lo relativo a actitudes más individuales en el puesto de trabajo. Logró, de hecho, una valoración positiva sin necesidad de apoyo en I I de los indicadores, y superó con apoyo verbal otros dos ( 2 y 5) y con apoyo gestual el indicador I 3 . Este alumno sólo fue evaluado negativamente en el indicador relativo a la capacidad de proponer mejoras en los procesos de trabajo. Por lo tanto, superó la evaluación de esta unidad de competencia y estaría en situación de presentarse a las pruebas de acreditación oficial de la competencia profesional si éstas incorporaran los "ajustes razonables previos" que se proponen.

En cuanto a la alumna, la evaluación relacionada con el "saber haciendo" deparó los siguientes resultados: los criterios de mérito I, 2 y 3 fueron superados con el nivel de desempeño adecuado y sin necesidad de apoyo; el criterio de mérito 4 fue superado con apoyo de tipo verbal por parte del evaluador; y el criterio de mérito 5 no fue superado, al incumplir las normas de prevención de riesgos laborales.

En el nivel de desempeño relacionado con el “saber estar”, la alumna evaluada no salvó el umbral establecido: superar sin apoyo ro de los 15 indicadores. Superó sin apoyo los relacionados con la tolerancia, el respeto, y la responsabilidad en el trabajo; además, superó con apoyos verbales dos indicadores ( 8 y I con apoyo gestual el indicador 6. Cabe destacar que en todos los indicadores logrados con alguno de los apoyos previstos, la interacción personal era necesaria. Los indicadores en los que la alumna no alcanzó el mínimo de competencia actitudinal requerido fueron los siguientes: 5, 9, I4 y I 5. Estos resultados son similares a los obtenidos en la evaluación continua de las actitudes a lo largo de las sesiones de la acción formativa; al igual que en la evaluación procedimental, el formador dio cuenta de la no superación de los indicadores relacionados con la propuesta de mejora de los procesos de trabajo, la resolución de problemas, y la seguridad y riesgos laborales. Por lo tanto, la alumna 5 no superó la evaluación de competencia.

\subsection{Propuesta de itinerarios de inserción laboral}

Una vez terminado el proceso de evaluación de competencias profesionales correspondientes a la unidad de competencia de operaciones básicas de montaje, se debe elaborar una propuesta de orientación hacia un itinerario de inserción en función de los resultados obtenidos y de la intensidad de apoyo que cada PcDI precisó. 
Recordemos que los itinerarios previstos con carácter general son:

- Acreditación oficial de la competencia profesional para inserción laboral en empresa ordinaria. Téngase en cuenta que las empresas con más de 50 empleados deben contratar por lo menos a un $2 \%$ de trabajadores con discapacidad.

- Programa de empleo con apoyo.

- Creación de un centro especial de empleo.

- Permanencia en el centro ocupacional, con la posibilidad de reforzar la formación recibida.

En el caso del alumno, se demuestra nítidamente la pertinencia de un itinerario de inserción laboral en empresa ordinaria a través de la cuota del $2 \%$ para personas con discapacidad, y se incide además en la formación en técnicas de búsqueda de empleo y el fomento de la implicación de las empresas de la comarca directamente relacionadas con este ámbito laboral. Como a día de hoy no es posible acreditar oficialmente esta unidad de competencia en Galicia, sería prioritario que la Asociación AMIPA instara a la Administración a desarrollar los procesos correspondientes.

Si en el momento de proceder a la contratación la adaptación del alumno no fuese la adecuada, podría diseñarse un programa de empleo con apoyo para realizar el proceso de adaptación; las dificultades de este procedimiento radican en los costes económicos que esta iniciativa representaría para la Asociación.

Para la alumna, difiere la propuesta de inserción laboral, dado que al no superar la evaluación de la competencia, se descarta la inserción en la empresa ordinaria y el empleo con apoyo. En función de los logros alcanzados y los apoyos recibidos, lo indicado sería un itinerario de inserción laboral en un sistema semiprotegido, como un centro especial de empleo, iniciativa totalmente adecuada a sus necesidades actuales. Con esta alternativa, podrá mantener las habilidades y destrezas relacionadas con la unidad de competencia evaluada, y también recibir la formación individualizada precisa para mejorar tanto en las áreas procedimentales en las que mostró carencias como en las actitudinales, de cara a una futura inserción en el mundo laboral ordinario. En el caso de que un número importante de participantes en la acción formativa obtuviesen resultados similares en el proceso de evaluación, la Asociación AMIPA podría plantearse la posibilidad de crear un centro de estas características.

\section{Conclusiones}

En este estudio se han explorado elementos relevantes para el desarrollo de procesos de inserción laboral de PcDI en puestos de trabajo que requieren habilidades específicas para su desempeño. En línea con la actual definición de discapacidad intelectual, la planificación y prestación de los apoyos necesarios para desarrollar la evaluación de competencias se convierte en imprescindible para maximizar el rendimiento personal y favorecer una mejoría en la calidad de vida de las PcDI. En este sentido, el proceso desarrollado nos permite avanzar las siguientes conclusiones:

- Eficacia del proceso formativo en la formación para el empleo. Los resultados de la evaluación de la competencia profesional proporcionan indicios positivos acerca de la posibilidad de entrenar y transferir a contextos laborales normalizados o con apoyo las habilidades adquiridas a través de la formación para el empleo. Se ha constatado la importancia de una formación preparatoria en habilidades técnicas y, de manera especial, la formación en habilidades sociales y personales para el desempeño de una profesión, así como para el mantenimiento del futuro puesto de trabajo. Por lo tanto, la formación que la PcDI recibe después de la etapa escolar tiene una importancia fundamental para su inserción laboral. De hecho, no se puede 
hablar de igualdad de oportunidades si no se inserta a los individuos en el mercado de trabajo, dado que una verdadera inclusión social es, fundamentalmente, de carácter sociolaboral.

- Incremento de igualdad de oportunidades. También podemos afirmar que el proceso contribuyó a mejorar la igualdad de oportunidades en el ámbito de la evaluación de competencias profesionales, introduciendo adaptaciones en dos momentos:

- En el diseño los instrumentos de evaluación, incorporando los apoyos precisos para que las personas con discapacidad tengan oportunidades de superar las pruebas, si es competente en su desempeño. Durante la evaluación, se demostró que, con los instrumentos adaptados, fueron capaces de ejecutar las tareas que se les demandaban, incluso, sin ayuda o apoyo del evaluador/formador.

- En la aplicación del proceso de evaluación, al tratar de evitar que la situación en sí supusiese una barrera que pudiese bloquear a las personas con discapacidad en la demostración de su desempeño. Por esto, el hecho de evaluar competencias en el entorno en el que desarrollan sus actividades cotidianas supone una importante adaptación que podría proponerse a la administración responsable de las acreditaciones, en el caso gallego, la Consellería de Cultura, Educación e Ordenación Universitaria. El proceso de acreditación oficial se lleva a cabo en centros de Formación Profesional, pero las recomendaciones del INCUAL indican que, de ser posible, se deberá evaluar a las personas en su puesto de trabajo. Desde nuestro punto de vista, se debería considerar un centro ocupacional como centro de trabajo, avanzando de esta manera en mecanismos que igualen en oportunidades a las PcDI.
- Optimización de los itinerarios formativos y de orientación laboral. Del proceso se deriva también una mejora en la concreción de los itinerarios formativos y de orientación laboral de las personas beneficiarias de los servicios del centro ocupacional, que redundará en la ampliación de las posibilidades de inserción profesional de las PcDI en la Comarca do Sar. La observación desarrollada en el proceso de evaluación nos permitió documentar los logros y dificultades que las personas evaluadas encontraron en la realización de las tareas laborales, así como planificar algunos apoyos que resultaron eficaces para alcanzar los umbrales de desempeño competente. También nos sirvió para comprobar que, para estas personas, los contenidos actitudinales pueden ser más difíciles de asimilar que los procedimentales, por lo que sería preciso intensificar la formación y evaluación en este ámbito, ya que las carencias en habilidades sociales pueden llevar a la pérdida del puesto de trabajo. Por lo tanto, en los procesos formativos destinados a PcDI el ámbito actitudinal se debe cuidar con especial atención.

Aunque se llevó a cabo una aplicación exploratoria limitada, consideramos que los resultados obtenidos avalan la posibilidad de que las PcDI puedan entrenarse y transferir a contextos laborales de empleo habilidades relacionadas con el desempeño de un perfil laboral concreto contemplado en el Catálogo Nacional de Cualificaciones Profesionales. En definitiva, a través del diseño y aplicación de instrumentos adaptados para la evaluación de competencias en PcDI, creemos que es posible avanzar en determinar la capacidad de desempeño en la unidad de competencia de operaciones básicas de montaje del alumnado con discapacidad intelectual de un centro ocupacional, con el fin de abordar sus posibilidades de inserción laboral y, consecuentemente, la mejora de su bienestar e inclusión social.

Queremos concluir afirmando que, en aplicación del principio de igualdad de oportunidades, 
si se introducen las adaptaciones oportunas en el proceso metodológico de evaluación de competencias profesionales, algunas PcDI debidamente formadas serán capaces de obtener resultados favorables que incrementen las posibilidades de inserción sociolaboral normalizada. O lo que es lo mismo, "de los programas basados en centros o edificios [...] pasar a ofrecer programas de integración real basados en la comunidad" (Valedor do
Pobo, 2013: I 56). Por lo tanto, se demuestra falso el principio que prejuzga a la persona con discapacidad como no rentable en el ámbito laboral y que las dificultades que encuentra la PcDI para acceder a un empleo no son exclusivamente suyas, sino también consecuencia del rechazo del sistema productivo del contexto -los factores ambientales subrayados por la OMS (200I)- en el que se desarrolla la persona.

\section{Referencias bibliográficas}

Alba, A. y Moreno, F. (2004): Discapacidad y mercado de trabajo, Madrid: Caja Madrid.

Albert, M.J. (2006): La investigación educativa: claves teóricas, Madrid: McGraw Hill.

Amor, J.R. (2010): Bioética y dependencia, A Coruña: Obra Social Caixa Galicia.

Becerra, M.T. et al. (2008): "Evaluación de un programa de apoyo laboral para trabajadores con discapacidad intelectual en tareas con elevada exigencia cognitiva". Siglo Cero, 226: 63-8I.

Blanco, A. (2008): "Formación universitaria basada en competencias”, en Prieto, L. (coord.), La enseñanza universitaria centrada en el aprendizaje. Barcelona: Octaedro.

Blas, F. (2007): Competencias profesionales en la Formación Profesional. Madrid: Alianza Editorial.

Bonsón, M. (2009): "Desarrollo de competencias en educación superior”, en Blanco, A. (coord.), Desarrollo y evaluación de competencias en educación superior. Madrid: Narcea.

Caride, J.A. et al. (2007): Educaçâo e desenvolvimento comunitário local.
Perspectivas pedagógicas e sociais da sustentabilidade. Porto: Profediçôes.

Cerrillo, R. e Izuzquiza D. (2010): "Desarrollo de competencias profesionales”, en De Miguel, S. y Cerrillo, R. (coords.), Formación para la inclusión laboral de personas con discapacidad intelectual. Madrid: Pirámide.

Colectivo Ioé (2012): Discapacidades e inclusión social. Barcelona: Fundación La Caixa.

- (2003): La inserción laboral de personas con discapacidades. Barcelona: Fundación La Caixa.

De Miguel, S. y Cerrillo, R. (coords.) (20I0): Formación para la inclusión laboral de personas con discapacidad intelectual. Madrid: Pirámide.

Egido, I. et al. (2009): "La inclusión social y laboral de las personas con discapacidad intelectual mediante los programas de empleo con apoyo. Un reto para la orientación". Revista Española de Orientación y Psicopedagogía, 20 (2): I35-I46.

España. Constitución Española. Boletín Oficial del Estado, núm. 3I I, de 29 de diciembre de 1978 , pp. 29.3 I3-29.424. 
España. Ley Orgánica 5/2002, de I9 de junio de 2002, de las Cualificaciones y de la Formación Profesional. Boletín Oficial del Estado, núm. I 47 , de 20 de junio de 2002, pp. 22.43722.442 .

España. Real Decreto I 224/2009, de I7 de julio, de reconocimiento de las competencias profesionales adquiridas por experiencia laboral. Boletín Oficial del Estado, núm. 205, de 25 de agosto de 2009, pp. 72.704-72.727.

FEAPS (I995): Modelo referencial de centro ocupacional (en línea). <http://www.feaps.org/ servicios/documentos/modelo_ocupacion.PDF>, acceso 4 de marzo de 2014 .

Fullana, J. et al. (2010): “¿Contribuye a la inclusión laboral la formación que recibe el alumnado con discapacidad intelectual en la ESO?". Revista Educación Inclusiva, 3: 5 I-66.

Galicia. Orden del I4 de enero de 20I4, por la que se convoca el proceso de acreditación de competencias profesionales adquiridas a través de la experiencia laboral, en la Comunidad Autónoma de Galicia, en determinadas unidades de competencia del Catálogo Nacional de Cualificaciones Profesionales. Diario Oficial de Galicia, núm. I4, de 22 de enero de 20I4, pp. 2.4I5-2.436.

Hegarty, S. (I994): Educación de niños y jóvenes con discapacidades. París: Unesco.

Ibañez, P. y Mudarra, M.J. (2007): Integración sociolaboral. Trabajadores con discapacidad intelectual en centros especiales de empleo. Madrid: Dykinson.

Instituto Galego das Cualificacións (2014): Datos ocupacionales. Contrataciones de peones de las industrias manufactureras en O Sar entre 2006-I 2 (en línea). <http://emprego.xunta.es/ cualificacions>, acceso 25 de enero de 20 I 4 .

Instituto Galego de Estatística (20I4): Empresas de fabricación de elementos metálicos para la construcción en la Comarca do Sar (en línea). $<$ http://www.ige.eu>, acceso 25 de enero de 20 I4 4

Instituto Nacional de las Cualificaciones (20I4): Guía de evidencia de la competencia profesional (en línea). <http://www.educacion.
gob.es/educa/incual/pdf/Acreditacion/Guias/ GEC_FMEo3 I_I.pdf>, acceso 25 de enero de 2014 .

- (20I4): Niveles de cualificación (en línea). $<$ http://www.educacion.gob.es/educa/incual/ ice_catalogoWeb.html>, acceso 25 de enero de 2014 .

Instituto Nacional de Estadística (20I4): Encuesta de Población Activa. Tasa de paro, cuarto trimestre 2013 (en línea). <http://www.ine.es/ inebaseDYN/epa30308/epa_inicio.htm>, acceso I 8 de marzo de 2014.

- (2013): El empleo de las personas con discapacidad. Explotación de la Encuesta de Población Activa y de la Base Estatal de Personas con Discapacidad. Año 2012 (en línea). <http://www.ine.es/prensa/np82I.pdf>, acceso I 4 de febrero de 2014.

- (20I I): Censo de Población y Viviendas 20 I I (en línea). <http://www.ine.es/censos2or I datos/cen I I_datos_inicio.htm>, acceso 25 de enero de 20I4.

Izuzquiza, L. y Ruiz, R. (2005): “Formación para la inserción laboral. Un proyecto conjunto entre la Facultad de Formación de Profesorado y Educación de la Universidad Autónoma de Madrid y la Fundación Prodis". Revista Sindrome de Down, 22: I25-I3 I.

Jurado, P. (I999): “La transición escuela/trabajo y la evaluación de personas con discapacidad", en Arnaiz, P. y Guerrero, C. (eds.). Discapacidad psíquica: formación y empleo. Málaga: Aljibe.

Luckasson, R. et al. (2002): Manual Retardation: Definition, Classification and Systems of Supports ( $10^{\text {th }}$ edition). Washington D.C.: American Association on Mental Retardation [traducido en M.A. Verdugo y C. Jenaro (2004): Retraso mental: definición, clasificación y sistemas de apoyos ( I o edición). Washington D.C.: American Association on Mental Retardation; Madrid: Alianza Editorial].

Marset, R. (200I): “Adaptación de juegos”, en Ventosa, J. y Marset, R. (coords.), Integración de personas con disminución psíquica en el tiempo libre. Madrid: CCS. 
Naciones Unidas (2006): Convención Internacional sobre los derechos de las personas con discapacidad, de I3 de diciembre de 2006 (en línea). <http://www.un.org/esa/socdev/enable/ documents/tccconvs.pdf $>$, acceso 25 de enero de 2014 .

Organización Mundial de la Salud (200I) CIF. Clasificación Internacional del Funcionamiento, de la Discapacidad y de la Salud. Madrid: Imserso.

Pallisera, M. (1996): Transición a la vida activa de las personas con discapacidad psíquica. Barcelona: EUB.

Pérez, M. (20II): "Nuevos escenarios de formación laboral para alumnos con discapacidad intelectual". Tendencias Pedagógicas, I 8: I73-206.

Riaño, A.M. (20I2): "Programa de cualificación inicial. Itinerario laboral y planificación centrada en las personas con necesidades diversas". Siglo Cero, 244: 6-20.

Schalock, R.L. et al. (2010): Intellectual Disability. Definition, Classification, and Systems of
Supports. I $^{\text {th }}$ Edition. Washington D.C.: American Association on Intellectual and Developmental Disabilities.

Struillou, M. (2004): "Evaluación y balance de competencias", en Sobrado, L. (ed.). Evaluación y orientación de competencias y cualificaciones profesionales. Barcelona: Estel.

Unión Europea. Directiva 2000/78CE del Consejo, de 27 de noviembre de 2000 , relativa al establecimiento de un marco general para la igualdad de trato en el empleo y la ocupación. Boletín Oficial de las Comunidades Europeas, 2 de diciembre de 2000, $\mathrm{L}_{3} \mathrm{O}_{3} / \mathrm{I} 6-\mathrm{L}_{3} \mathrm{O}_{3} / 22$.

Valedor do Pobo (20I4): Informe extraordinario 2014 sobre los derechos de las personas con discapacidad intelectual (en línea). $<$ http://www.valedordopobo.com/index. php? s= I I $5 \&$ i= I $32 \&$ l=es $>$, acceso 9 de febrero de 2014 .

Verdugo, M.A. y Schalock, R.L. (20ıо): "Últimos avances en el enfoque y concepción de las personas con discapacidad intelectual". Siglo Cero, 236: 7-2I. 